\title{
Surveillance Publishing
}

\author{
JEFF POOLEY
}

In April 1998, two Stanford graduate students, Sergey Brin and Larry Page, flew across the world to deliver a paper on their nascent search engine, Google. Speaking at the Seventh International World Wide Web conference (WWW 1998) in Brisbane, Australia, Brin and Page described how their approach—taking the web's existing link "graph" as a proxy for quality and relevance-improved on the classified-by-hand indexes of Yahoo!, Lycos, and the like (Büttcher, Clarke, and Cormack 2016, 554; Brin and Page 1998). Six months later, they took their idea commercial, with the pair working out of a nearby garage. Within two years, Brin and Page had dispatched their search engine rivals and were on the way to building the largest advertising business in the history of capitalism.

Google's dorm-to-garage origin story is well known. Less famous is the debt that Brin and Page owed to library science and the field of bibliometrics. As the pair acknowledged in Brisbane, their key idea - to use the web's link structure as a plebiscite for search relevance-was borrowed from citation analysis. "The citation (link) graph of the Web," they said, "is an important resource that has largely gone unused in existing search engines" (Brin and Page 1998, 109). A given web page's "PageRank," they explained, is a measure of its "citation importance," which turns out to match, with uncanny consistency, what searchers want to find. Their approach, they continued, is an extension of the "[a]cademic citation literature" (109).

The Google founders had taken the core insight of bibliometrics, a field that emerged in the 1960s to study (among other things) the web of academic citations. As the historian of science Derek J. de Solla Price $(1965,510)$ put it in a seminal paper, citations furnish a "total world network of scientific papers." By the early 1970s, on the strength of computing advances, full-fledged citation analysis was being used to measure journal impacts, scientific productivity, and the structure of academic influence.

Two decades later in Brisbane, Brin and Page (1998) positioned Google as the academic antidote to ad-driven search engines. They complained that companies like Yahoo! wouldn't make their methods public, with the result that search technology remains "largely a black art" (109). With Google, they said, "we have a strong goal to push more development and understanding into the academic realm" (109). In a now notorious appendix to their published talk, the two graduate students decried the 
ad-driven business model of their commercial rivals. "We expect," Brin and Page wrote, "advertising funded search engines will be inherently biased towards the advertisers and away from the needs of the consumers" - a "particularly insidious bias," they added, since it's so hard to detect $(2012,3832){ }^{1}$

They changed their minds. In the face of the 2001 dot-com meltdown and investor demands, Brin and Page-to borrow the Silicon Valley verb—pivoted. As Shoshana Zuboff (2019, chap. 3) has documented, the company went all in with ads: targeted ads, informed by the user data trove the company had laying about. By 2004, the company had gone public, valued at $\$ 27$ billion (La Monica 2004). Harnessing its search-and-services-derived user data, Google went on to capture almost $30 \%$ of worldwide digital ad revenue (Cramer-Flood 2021). Today the market value of Alphabet, Google's parent company, hovers around $\$ 2$ trillion. Built up from academic citation analysis, the company is the defining example of what Zuboff (2019) calls "surveillance capitalism."

There is another irony. The field of bibliometrics, all the way back to its early 1960s emergence, was already enmeshed in data capitalism. Here again, the story is well known: Eugene Garfield, a would-be chemist turned science entrepreneur, established his science indexing business, the Institute for Scientific Information (ISI), in the mid-1950s (Wouters 2017). In 1964, Garfield's ISI produced the first Science Citation Index, a database of published papers and their citations (Garfield 2006, 1127). Bibliometrics pioneers such as de Solla Price partnered with Garfield to mine the service's database-hence de Solla Price's total world network of scientific papers. Other ISI indexes for the social sciences and for the arts followed in the 1970s, when Garfield's firm also began publishing its Journal Citation Reports (Garfield 1975; Trolley and O'Neill 1999, 126; Baykoucheva 2019, 4-5). In 1992, with the World Wide Web in its infancy, Garfield sold ISI to Thomson, the Canadian information giant (Pendlebury $2020,27)$. The business traded hands again in 2016, in a private equity spinoff called Clarivate. Garfield's citation index-now called the Web of Science-stood at the center of the $\$ 3.5$ billion deal (Clarivate 2021, 13).

From the Web of Science back to the web, in fundamental ways Clarivate's business resembles Alphabet's. Clarivate, of course, doesn't feed from the advertising firehouse like Google does. But both companies mine behavior for data, which they process into prediction products. In Google's case, we're all in on the action, with every search and email; once refined, the data is sold to the company's customer-advertisers for targeted display. Clarivate's behavioral data is harvested from a much smaller publicworking academics — who, in another difference from Google, are the company's main

1. The appendix appeared in some versions of the 1998 conference paper write-up. Page numbers are from a reprint (Brin and Page 2012). 
customers too. But the core business strategy is the same: extract data from behavior to feed predictive models that, in turn, get refined and sold to customers. In one case it's search terms and in the other abstracts and citations, but either way the point is to mint money from the by-products of (consumer or scholarly) behavior. In place of Google's propensity to buy, Clarivate is selling bets on future scholarly productivity and impact, among other academic prediction products.

This article lingers on a prediction too: Clarivate's business model is coming for scholarly publishing. Google is one peer, but the company's real competitors are Elsevier, Springer Nature, Wiley, Taylor \& Francis, and SAGE. Elsevier, in particular, has been moving into predictive analytics for years now. Of course the publishing giants have long profited off of academics and our university employers—by packaging scholars' unpaid writing-and-editing labor only to sell it back to us as usuriously priced subscriptions or article processing charges (APCs). That's a lucrative business that Elsevier and the others won't give up. But they're layering another business on top of their legacy publishing operations, in the Clarivate mold. The data trove that publishers are sitting on is, if anything, far richer than the citation graph alone.

Why worry about surveillance publishing? One reason is the balance sheet, since the companies' trading in academic futures will further pad profits at the expense of taxpayers and students. The bigger reason is that our behavior-once alienated from us and abstracted into predictive metrics-will double back onto our work lives. Existing biases, like male academics' propensity for self-citation, will receive a fresh coat of algorithmic legitimacy. More broadly, the academic reward system is already distorted by metrics. To the extent that publishers' tallies and indices get folded into grant-making, tenure and promotion, and other evaluative decisions, the metric tide will gain power. The biggest risk is that scholars will internalize an analytics mindset, one already encouraged by citation counts and impact factors.

Useful as it is, Zuboff's (2019) notion of surveillance capitalism is too tightly drawn around a relatively small pocket of the economy, digital advertising. That same narrowed aperture led Zuboff, in The Age of Surveillance Capitalism, to over-emphasize the novelty of the behavioral futures business she attributes to Google. The insurance (Bouk 2015) and credit-rating (Lauer 2017) industries, to mention two, have hitched data to predictive profit for well over a hundred years (Breckenridge 2020, 933; Jansen and Pooley 2021, 2845). As we have seen, Garfield's ISI was in the data business before Larry Page and Sergey Brin were born.

To get at the publishers' kinship with Google or, for that matter, the Hartford, we need a broader descriptor. The legal scholars Mariano-Florentino Cuéllar and Aziz Huq $(2020,1307)$ have proposed a pluralized alternative, "surveillance economies," to refer to the range of business models that seek to monetize behavioral data. "As more industries find ways to incorporate behavioral surpluses into their business models," 
they write, "the share of the economy that falls under this term will increase, perhaps dramatically." Cuéllar and Huq foreground the pluralism: The specific contours of any given surveillance economy will vary, based on sector-specific norms and regulations. There is, in other words, no need to take the analogy to Google too far. Data businesses based on academics' citations and downloads are unlikely to emulate Google's ad-driven model. The big publishers, along with Clarivate and other potential players, are more likely to piggyback on their existing subscription strategy, with data products licensed to university and other research clients. Either way, they'll be lapping up the behavioral surplus that scholars produce.

The publishers are in an enviable position, since researchers generate data with every article engagement or peer review report. Some of that data gets folded into the publishers' core products, by way of download counts and article recommendations. But we have every reason to believe, based on existing data products alone, that publishers are skimming scholars' behavioral residue on the prospect of monetization to come. In an important recent paper, science and technology studies (STS) scholar Jathan Sadowski (2019) took issue with the commonplace that data is the "new oil." On the commodity view that he challenges, data is raw material for other products, easy to exchange for cash. Data is often a commodity like this, Sadowski concedes; the sprawling data brokerage industry is an illustration in point. But it's also useful to think about data as capital, in the specific sense of "capital" developed by the late French sociologist Pierre Bourdieu. Data capital resembles in form something like Bourdieu's cultural capital: Though a learned appreciation for abstract art can, in certain conditions, lead to a lucrative job, the value of that cultural capital isn't merely, or even mainly, monetary. Data capital, likewise, can be converted into dollars in some contexts. But its value to owners may lie elsewhere. Firms may use data to guide strategy, refine workflows, or train models, among other things. Like social or cultural capital, there is a prospective quality to data accumulation - an incentive to hoard on the expectation of future value. $^{2}$

Scholarly publishing is its own, emerging surveillance economy. We can call a company a surveillance publisher if it derives a substantial proportion of its revenue from prediction products, fueled by data extracted from researcher behavior. On that definition, we already have surveillance publishers in our midst.

Consider Elsevier. The Dutch publishing house was founded in the late nineteenth century, but it wasn't until the 1970s that the firm began to launch and acquire journal titles at a frenzied pace. Elsevier's model was Pergamon, the postwar science publishing

2. Sadowski $(2019,4)$ quotes Marion Fourcade and Kieran Healy $(2017,13)$ on this point: "It does not matter that the amounts [of data] collected may vastly exceed a firm's imaginative reach or analytic grasp. The assumption is that it will eventually be useful, i.e. valuable." 
venture established by the brash Czech-born Robert Maxwell (Buranyi 2017). By 1965, around the time that Garfield's Science Citation Index first appeared, Pergamon was publishing 150 journals. Elsevier followed Maxwell's lead, growing at a rate of 35 titles a year by the late 1970s. Both firms hiked their subscription prices aggressively, making huge profits off the prestige signaling of Garfield's Journal Impact Factor. Maxwell sold Pergamon to Elsevier in 1991, months before his lurid death (Buranyi 2017).

Elsevier was just getting started. The firm acquired The Lancet the same year, when the company piloted what would become ScienceDirect, its web-based journal delivery platform (Elsevier 2005, 7; Zijlstra 1994, 169). In 1993, the Dutch publisher merged with Reed International, a UK paper-maker turned media conglomerate. In 2015, the firm changed its name to RELX Group, after two decades of acquisitions, divestitures, and product launches-including Scopus in 2004, Elsevier's answer to ISI's Web of Science. The "shorter, more modern name," $\operatorname{RELX}(2016,3)$ explained, is a nod to the company's "transformation" from publisher to a "technology, content and analytics driven business." RELX's strategy? The "organic development of increasingly sophisticated information-based analytics and decisions tools" (RELX Group, 2016, 4). Elsevier, in other words, was to become a surveillance publisher.

Since then, by acquisition and product launch, Elsevier has moved to make good on its self-description. By moving up and down the research lifecycle, the company has positioned itself to harvest behavioral surplus at every stage (Posada and Chen, 2017, 2018). Tracking lab results? Elsevier has Hivebench, acquired in 2016. Citation and data-sharing software? Mendeley, purchased in 2013. Posting your working paper or preprint? SSRN and bepress, 2016 and 2017, respectively.

Elsevier's "solutions" for the post-publication phase of the scholarly workflow are anchored by Scopus and its 81 million records. Curious about impact? Plum Analytics, an altmetrics company, acquired in 2017. Want to track your university's researchers and their work? There's the Pure "research information management system," acquired in 2012. Measure researcher performance? SciVal, spun off from Scopus in 2009, which incorporates the media monitoring service Newsflo, acquired in 2015.

Elsevier, to repurpose a computer science phrase, is now a full-stack publisher. Its products span the research lifecycle, from the lab bench through to impact scoring, and even - by way of Pure's grant-searching tools-back to the bench, to begin anew. Some of its products are, you might say, services with benefits: Mendeley, for example, or even the ScienceDirect journal delivery platform, provides reference management or journal access for customers and gives behavioral data to Elsevier. Products such as SciVal and Pure, up the data chain, sell the processed data back to researchers and their employers, in the form of "research intelligence."

It's a good business for Elsevier. Facebook, Google, and ByteDance have to give away their consumer-facing services to attract data-producing users. If you're not 
paying for it, the Silicon Valley adage has it, then you're the product. For Elsevier and its peers, we're the product and we're paying (a lot) for it. Indeed, it's likely that windfall subscription and APC profits in Elsevier's "legacy" publishing business have financed its decade-long acquisition binge in analytics. ${ }^{3}$ This is insult piled onto injury: Fleece us once only to fleece us all over again, first in the library and then in the assessment office.

Elsevier's prediction products sort and process mined data in a variety of ways. The company touts what it calls its Fingerprint Engine, which applies machine learning techniques to an ocean's worth of scholarly texts-article abstracts, yes, but also patents, funding announcements, and proposals (Elsevier n.d.-a). Presumably trained on human-coded examples (scholar-designated article keywords?), the model assigns keywords (e.g., "drug resistance") to documents, together with what amounts to a weighted score (e.g., 73\%). The list of terms and scores is, the company says, a "fingerprint." The engine is used in a variety of products, including Expert Lookup (to find reviewers), the company's JournalFinder, and its Pure university-level research management software. In the latter case, it's scholars who get fingerprinted: "Pure applies semantic technology and 10 different research-specific keyword vocabularies to analyze a researcher's publications and grant awards and transform them into a unique Fingerprint $\mathrm{t}^{\mathrm{TM}}$ - $\mathrm{a}$ distinct visual index of concepts and a weighted list of structured terms" (Elsevier n.d.-b).

The machine learning techniques that Elsevier is using are of a piece with RELX's other predictive analytics businesses aimed at corporate and legal customers, including LexisNexis Risk Solutions (RELX Group 2021; van Loon n.d.). Though RELX doesn't provide specific revenue figures for its academic prediction products, the company's 2020 SEC disclosures indicate that over a third of Elsevier's revenue comes from databases and electronic reference products - a business, the company states, in which "we continued to drive good growth through content development and enhanced machine learning and natural language processing based functionality" (RELX Group 2021, 18).

Many of Elsevier's rivals appear to be rushing into the analytics market, too, with a similar full research-stack data harvesting strategy. Taylor \& Francis, for example, is a unit of Informa, a UK-based conglomerate whose roots can be traced to Lloyd's List, the eighteenth-century maritime intelligence journal. In its 2020 annual report, the company wrote that it intends to "more deeply use and analyze the first party data" sitting in Taylor \& Francis and other divisions to "develop new services based on

3. As Björn Brembs (2021b) recently tweeted, "Massive over-payment of academic publishers has enabled them to buy surveillance technology covering the entire workflow that can be used not only to be combined with our private data and sold, but also to make algorithmic (aka. 'evidence-led') employment decisions." See also Brembs (2021a) and Posada and Chen (2017, 2018). 
hard data and behavioral data insights" (Informa Group 2021, 17). Last year Informa acquired the Faculty of 1000, together with its OA F1000Research publishing platform. Not to be outdone, Wiley bought Hindawi, a large independent OA publisher, along with its Phenom platform. The Hindawi purchase followed Wiley's 2016 acquisition of Atypon, a researcher-facing software firm whose online platform, Literatum, Wiley recently adopted across its journal portfolio. "Know thy reader," Atypon (n.d.) writes of Literatum. "Construct reports on the fly and get visualization of content usage and users' site behavior in real time." Springer Nature, to cite a third example, sits under the same Holtzbrinck corporate umbrella as Digital Science, which incubates startups and launches products across the research lifecycle, including the Web of Science/Scopus competitor Dimensions, data repository figshare, impact tracker Altmetric, and many others.

The big publishing oligopolists aren't the only firms looking to profit from researcher behavior. There is, of course, Clarivate itself, whose $\$ 5.3$ billion purchase of ProQuest is currently stalled over regulatory concerns (Milliot 2021). The two venture-backed academic social networks, Academia and ResearchGate, re-package researchers' activity on their sites via user analytics; observers have speculated for years that the companies will build analytics products based on their data troves. ResearchGate (n.d.) is already selling a jobs search tool as well as targeted advertising ("Upgrade your targeting options with sophisticated Sequential Ads"). Surveillance businesses focused on other facets of nonprofit higher ed - student life, for example, or the classroom — are growing too. Online program management (OPM) firms, a business Wiley is also in, are going public with multi-billion-dollar valuations predicated, according to news reports, on the value of their tens of millions of "learner" profiles. Likewise with venture-funded $\mathrm{EAB}$, which touts its data-driven academic advising software as the first enterprise-level "student management system." Even Google itself could, at any moment, decide to monetize its Google Scholar search engine-in what would be a return, a fitting one, to its bibliometrics roots.

Siphoning taxpayer, tuition, and endowment dollars to access our own behavior is a financial and moral indignity. That we are paying the sellers a second time, after budget-draining subscription and APC outlays, is a scandal. Elsevier made $\$ 1.4$ billion in profit last year, on $\$ 3.6$ billion in revenue-a profit margin of 38\% (RELX Group $2021,18)$. That lucrative business is built on scholars' unpaid labor, as subsidized by our university employers. The typeset product of that labor, in a long-standing complaint, is sold back to us at extortionate prices. Now Elsevier is skimming the behavioral cream and selling that too. If anything, profits from the first business have financed the build-up of the second.

Consider, too, the intended use of these surveillance products. The customers for many of the predictive analytics sold by Elsevier and others are university administrators 
and national research offices. The products' purpose is to streamline the top-down assessment and evaluation practices that have taken hold in recent decades, especially across the Anglophone academy. Some of the practices, and most of the mindset, are borrowed from the business sector. To varying extent, the zeal for measurement is driven by the idea that the university's main purpose is to grow regional and national economies. Products like Pure and SciVal are, or will be, among the quantified tools by which economic and engineering values shape what we mean by higher education. At the very least, their dashboard tabulations will be deployed to justify "program prioritization" and other budgetary re-allocations. As Ted Porter $(1995,8)$ has observed, quantification is a way of making decisions without seeming to decide.

In that sense, the "decision tools" peddled by surveillance publishers are laundering machines - context-erasing abstractions of our messy academic realities. ${ }^{4}{ }^{2} t^{\prime}$ 's true that the standard research article, and even its underlying datasets, are already abstracted. But black box researcher productivity scores, to take one example, are at another remove from our knowledge-making practices. One reason this matters is that algorithmic scores and indices can camouflage the biases that structure academic life. Consider center-periphery dynamics along North-South and native-English-speaking lines: Gaps traceable to geopolitical history, including the legacy of European colonialism, may be buried still deeper under the weight of proprietary metrics.

The problem isn't merely camouflage. With all the authority granted quantitative measure, up to and including funding and hiring decisions, predictive scoring might make smuggled-in biases worse. As a number of scholars have shown, metrics and rankings help enact the world that they purport to merely describe (e.g., Espeland and Sauder 2007; Espeland and Stevens 2008; Fourcade and Johns 2020). Thus, native English speakers might appear more likely to produce impactful papers, based on past citation data used to train a predictive algorithm—a measure that could, in turn, justify a grant award. Such dynamics of cumulative advantage would serve to widen existing disparities—a Matthew effect on the scale of Scopus.

The looping effects of algorithmic scoring may include playing to the measure. As Goodhart's Law (Chrystal 2003) has it, when a measure becomes a target, it ceases to be a good measure. Scholars, like other subjects of ranked measurement, may "optimize" their papers to appeal to the algorithm. If grants, promotion, and recognition follow, such behavior will reinforce an already metricized reward system. We may tweak our work to be, in Tarleton Gillespie's $(2017,64)$ phrase, algorithmically recognizable, or even to see ourselves through the prism of Elsevier's predictive analytics.

4. On the broader context of artificial intelligence/machine learning abstraction, see Crawford (2021). 


\section{References}

Atypon. n.d. "Literatum." https://www.atypon.com/products/literatum/.

Baykoucheva, Svetla. 2019. "Eugene Garfield's Ideas and Legacy and Their Impact on the Culture of Research.” Publications 7, no. 2: 43. https://doi.org/10.3390/publications7020043.

Bouk, Dan. 2015. How Our Days Became Numbered: Risk and the Rise of the Statistical Individual. Chicago: University of Chicago Press.

Breckenridge, Keith. 2020. "Capitalism without Surveillance?" Development and Change 51, no. 3: 921-35.

Brembs, Björn. 2021a. "Algorithmic Employment Decisions in Academia?” björn.brembs.blog, September 23. http://bjoern.brembs.net/2021/09/algorithmic-employment-decisions-in-academia/.

Brembs, Björn (@brembs). 2021b. "Massive over-payment of academic publishers has enabled them to buy surveillance technology covering the entire workflow that can be used not only to be combined with our private data and sold, but also to make algorithmic (aka. 'evidence-led') employment decisions." Twitter, September 23. https://twitter.com/brembs/status/1440942564094402560?s=21.

Brin, Sergey, and Lawrence Page. 1998. "The Anatomy of a Large-Scale Hypertextual Web Search Engine." Computer Networks and ISDN Systems 30, no. 1-7: 107-17. https://doi.org/10.1016/ S0169-7552(98)00110-X.

Brin, Sergey, and Lawrence Page. 2012. "Reprint of: The Anatomy of a Large-Scale Hypertextual Web Search Engine.” Computer Networks 56, no. 18: 3825-33. https://doi.org/10.1016/j.comnet.2012.10.007.

Buranyi, Stephen. 2017. "Is the Staggeringly Profitable Business of Scientific Publishing Bad for Science?” The Guardian, June 27. https://www.theguardian.com/science/2017/jun/27/profitablebusiness-scientific-publishing-bad-for-science.

Büttcher, Stefan, Charles L. A. Clarke, and Gordon V. Cormack. 2016. Information Retrieval: Implementing and Evaluating Search Engines. Cambridge, MA: MIT Press.

Chrystal, Alec. 2003. "Goodhart's Law: Its Origins, Meaning and Implications for Monetary Policy." In Central Banking, Monetary Theory and Practice: Essays in Honour of Charles Goodhart, volume 1, edited by Paul D. Mizen, 221-43. Northampton, MA: Edward Elgar.

Clarivate. 2021. Form 10-K 2020. Jersey, Channel Islands: Clarivate.

Cramer-Flood, Ethan. 2021. "Duopoly Still Rules the Global Digital Ad Market, but Alibaba and Amazon Are on the Prowl." eMarketer, May 10. https://www.emarketer.com/content/duopolystill-rules-global-digital-ad-market-alibaba-amazon-on-prowl.

Crawford, Kate. 2021. Atlas of AI. New Haven, CT: Yale University Press.

Cuéllar, Mariano-Florentino, and Aziz Huq. 2020. "Economies of Surveillance." Harvard Law Review 133, no. 4: 1280-336.

Elsevier. 2005. A Short History of Elsevier. London: Reed Elsevier. http://www.ask-force.org/web/ Seralini/Elsevier-Short-History-2005.pdf.

Elsevier. n.d.-a. "Elsevier Fingerprint Engine." Accessed November 16, 2021. https://www.elsevier. $\mathrm{com} /$ solutions/elsevier-fingerprint-engine.

Elsevier. n.d.-b. "[Pure] Features.” Accessed November 16, 2021. https:/www.elsevier.com/solutions/ pure/features.

Espeland, Wendy Nelson, and Michael Sauder. 2007. "Rankings and Reactivity: How Public Measures Recreate Social Worlds." American Journal of Sociology 113, no. 1: 1-40. https://doi. org/10.1086/517897.

Espeland, Wendy Nelson, and Mitchell L. Stevens. 2008. "A Sociology of Quantification.” European Journal of Sociology 49, no. 3: 401-36. https://doi.org/10.1017/S0003975609000150. 
Fourcade, Marion, and Kieran Healy. 2017. "Seeing Like a Market." Socio-Economic Review 15, no. 1: 9-29. https://doi.org/10.1093/ser/mww033.

Fourcade, Marion, and Fleur Johns. 2020. "Loops, Ladders and Links: The Recursivity of Social and Machine Learning." Theory and Society 49, no. 5: 803-32. https://doi.org/10.1007/s11186-02009409-x.

Garfield, Eugene. 1975. Journal Citation Reports. Philadelphia: Institute for Scientific Information.

Garfield, Eugene. 2006. "Commentary: Fifty Years of Citation Indexing." International Journal of Epidemiology 35, no. 5: 1127-28. https://doi.org/10.1093/ije/dyl190.

Gillespie, Tarleton. 2017. "Algorithmically Recognizable: Santorum's Google Problem, and Google’s Santorum Problem." Information, Communication \& Society 20, no. 1: 63-80. https://doi.org/ 10.1080/1369118X.2016.1199721.

Informa Group. 2021. Depth \& Data: Informa Group Annual Report and Accounts 2020. London: Informa Group.

Jansen, Sue Curry, and Jefferson Pooley. 2021. "Blurring Genres and Violating Guild Norms: A Review of Reviews of The Age of Surveillance Capitalism." New Media \& Society 23, no. 9: 2839-51. https:// doi.org/10.1177\%2F14614448211019021.

La Monica, Paul R. 2004. "Google Jumps 18\% in Debut." CNN Money, August 19. https://money. cnn.com/2004/08/19/technology/goog/.

Lauer, Josh. 2017. Creditworthy: A History of Consumer Surveillance and Financial Identity in America. New York: Columbia University Press.

Milliot, Jim. 2021. “Clarivate Purchase of ProQuest Delayed.” Publishers Weekly, August 11. https:// www.publishersweekly.com/pw/by-topic/industry-news/industry-deals/article/87120-clarivatepurchase-of-proquest-extended.html.

Pendlebury, David A. 2020. "Eugene Garfield and the Institute for Scientific Information." In Handbook Bibliometrics, edited by Rafael Ball, 27-40. Boston: De Gruyter Saur. https://doi. org/10.1515/9783110646610-005.

Porter, Theodore M. 1995. Trust in Numbers: The Pursuit of Objectivity in Science and Public Life. Princeton, NJ: Princeton University Press.

Posada, Alejandro, and George Chen. 2017. "Publishers Are Increasingly in Control of Scholarly Infrastructure and Why We Should Care: A Case Study of Elsevier." The Knowledge G.A.P., September 20. http://knowledgegap.org/index.php/sub-projects/rent-seeking-and-financialization-of-the-academic-publishing-industry/preliminary-findings/.

Posada, Alejandro, and George Chen. 2018. "Inequality in Knowledge Production: The Integration of Academic Infrastructure by Big Publishers." ELPUB 2018. https://doi.org/10.4000/proceedings. elpub.2018.30.

Price, Derek J. de Solla. 1965. "Networks of Scientific Papers." Science 149, no. 3683: 510-15. https:// doi.org/10.1126/science.149.3683.510.

RELX Group. 2016. Annual Report and Financial Statements 2015. London: RELX Group.

RELX Group. 2021. Form 20-F 2020. London: RELX Group.

ResearchGate. n.d. "Connect with Scientists Where They Do Their Research." https://www.researchgate.net/marketing-solutions.

Sadowski, Jathan. 2019. "When Data Is Capital: Datafication, Accumulation, and Extraction." Big Data \& Society 6, no. 1: 1-12. https://doi.org/10.1177\%2F2053951718820549.

Trolley, Jacqueline, and Jill O'Neill. 1999. "The Evolution of Citation Indexing-from Computer Printout to the Web of Science." In Proceedings of the 1998 Conference on the History and Heritage of Science Information Systems, edited by Mary Ellen Bowden, Trudi Bellardo Hahn, and Robert V. Williams, 124-26. Medford, NJ: Information Today. 
van Loon, Ronald. n.d. "The Future of Technology: Machine Learning at RELX Group." RELX Group. https://www.relx.com/our-business/our-stories/the-future-of-tech.

Wouters, Paul. 2017. "Eugene Garfield (1925-2017).” Nature 543 (March 23): 492. https://doi. org/10.1038/543492a.

Zijlstra, Jaco. 1994. "The University Licensing Program (TULIP): A Large Scale Experiment in Bringing Electronic Journals to the Desktop." Serials 7, no. 2: 169-72.

Zuboff, Shoshana. 2019. The Age of Surveillance Capitalism: The Fight for a Human Future at the New Frontier of Power. New York: PublicAffairs. 
